Substance Abuse Treatment and Motor Vehicle Fatalities

\author{
Beth A. Freeborn \\ College of William and Mary
}

Brian McManus

Olin School of Business at Washington University

College of William and Mary

Department of Economics

Working Paper Number 66

December 2007 
COLLEGE OF WILLIAM AND MARY

DEPARTMENT OF ECONOMICS

WORKING PAPER \# 66

December 2007

\title{
Substance Abuse Treatment and Motor Vehicle Fatalities
}

\begin{abstract}
The danger of alcohol- and drug-impaired driving implies that policies that reduce substance abuse can save lives. Using several estimation approaches, we show that a US county's supply of substance abuse treatment facilities is negatively and significantly related to the county's number of motor vehicle deaths. We find that placing an additional treatment clinic in a county reduces the number of vehicle fatalities by $8 \%$. An additional outpatient clinic, which specializes in treating the local population, can reduce the overall number of traffic deaths by $13 \%$ and the number of alcohol-related deaths by $24 \%$.
\end{abstract}

JEL Codes: I1, I18, K42

Keywords: $\quad$ substance abuse, alcohol, motor vehicle fatalities, drunk driving

Beth A. Freeborn

Department of Economics

College of William and Mary

Williamsburg, VA 23187-8795

bafree@wm.edu
Brian McManus

Department of Economics

Olin School of Business at Washington University

St Louis. MO 63130

mcmanus@wustl.edu 


\section{Introduction}

In recent years, motor vehicle accidents have lead to over 40,000 deaths annually in the United States, and alcohol-related accidents account for about $40 \%$ of these deaths. Legally drunk drivers are much more dangerous on the road than sober drivers, ${ }^{1}$ so considerable effort has been devoted to reducing the incidence of alcohol-impaired driving. Policies targeting drunk driving include alcohol taxes, increases in the legal drinking age, educational efforts, more stringent blood alcohol content (BAC) limits, and increased punishments for those arrested for driving under the influence of alcohol (DUI). ${ }^{2}$ In this paper we evaluate the impact of an additional policy instrument for reducing the incidence of drunk driving: the supply of substance abuse treatment (SAT).

In 2006 over 2.6 million people received treatment in the US for alcohol abuse. When drug addiction treatment is included, this figure grows to 4 million. ${ }^{3}$ There is abundant evidence that SAT reduces drug and alcohol abuse, specifically among heavy users. ${ }^{4}$ A reduction in dangerous driving behavior is just one of the positive effects of successful SAT; others include improvements in physical health, employment performance, and happiness at home. Substance abuse treatment also has the advantage of being a lower-cost approach to consumption reduction compared to criminal justice interventions in alcohol and drug abuse. $^{5}$

In order to assess the impact of increased SAT on reductions in traffic fatalities, we would ideally observe data on: the individuals who may receive treatment, the individuals who do receive treatment, the effect of treatment on drug and alcohol consumption, and finally the

\footnotetext{
${ }^{1}$ Levitt and Porter (2001) estimate that drunk drivers are 15 times more likely than sober drivers to cause a fatal accident.

${ }^{2}$ Benson, Rasmussen and Mast (1999) discuss the effectiveness of these policies.

${ }^{3}$ National Survey on Drug Use and Health (2006).

${ }^{4}$ For examples, see Lu and McGuire (2002) or Saffer, Chaloupka and Dave (2002). Predergast, Podus, Chang, and Urada (2002) perform a meta-analysis on the 'effectiveness of treatment' literature (78 studies) and show that clients who receive treatment have statistically more positive outcomes than those who do not receive treatment.

${ }^{5}$ Specifically, substance abuse treatment is believed to be more cost-effective than punishment. A prominent RAND study (Rydell and Everingham (1994)) finds that treatment is 7 times more cost effective than domestic law enforcement, 10 times more effective than interdiction, and 23 times more effective than the "source control" method (attacking drug supply abroad). Cartwright (2000) provides a detailed review of the literature on cost-benefit analysis of treatment and concludes that although there is a great deal of variation in the literature, the general persistent finding is that the benefit of substance abuse treatment outweighs the costs.
} 
differences in driving behavior of the treated and untreated populations. Data at this level of detail on substance abuse, treatment, and driving are simply unavailable, so in this paper we employ coarser measures of SAT in the US. ${ }^{6}$ We observe the numbers of SAT clinics and traffic fatalities in each US county, and we estimate the impact of a change in the count of clinics on fatalities. We effectively assume that an increase in SAT clinics reduces the costs or inconvenience for the local population to receive treatment. As more individuals receive treatment the safety of driving behavior increases on local roads. Our approach, therefore, is conservative in the sense that we do not capture the opportunity of one county's residents to take treatment in a neighboring county, or the beneficial impact of successful SAT on driving in areas other than a person's home county.

We face a considerable challenge in establishing a causal link between SAT and traffic fatalities. Even if increasing SAT truly reduces dangerous driving, many factors that are difficult or impossible to observe can interfere with correctly making this inference. For example, counties with populations that, in unobserved ways, are especially prone to alcohol and drug abuse could have both high rates of auto fatalities and a large number of SAT clinics. Alternatively, it could be the case that some counties are particularly aggressive in treating substance-related disorders and minimizing their impact on drivers, and these counties would have both more SAT clinics and fewer deaths. We address this challenge by taking a variety of empirical approaches to the data, including fixed effects where possible and employing instrumental variables. Our instruments include the number of practicing psychiatrists within a county and state regulatory variables regarding parity for mental health and substance abuse care; both sets of instruments shift the number of clinics while being unrelated to factors that affect road safety.

Our results indicate that the number of clinics and the number of clinics offering outpatient treatment are negatively and significantly related to the number of motor vehicle fatalities. Moreover, the availability of SAT has its greatest proportional effect on alcohol-

\footnotetext{
${ }^{6}$ For an example of research that is able to more closely observe the activity within communities following changes to SAT, see Hingson, Zakols, Heeren, Winter, Rosenbloom and DeJong (2005). The authors study five communities which received grants under the Robert Wood Johnson Foundation's "Fighting Back" program. These communities experienced declines in their ratios of alcohol-related to non-alcohol traffic fatalities. Due to the population sizes of these Fighting Back communities, the affected areas are not included in the data sample of the present paper.
} 
related motor vehicle deaths. The relationship between treatment and non-alcohol fatalities generally is not significant. On average, increasing the number of clinics by one in all of our sample counties would reduce the number of motor vehicle deaths by $8 \%$ each year. Increasing the number of clinics that specifically offer outpatient treatment services could reduce the number of motor vehicle deaths by $13 \%$ per year and the number of alcohol-related traffic deaths by $24 \%$ per year.

\section{Previous Research}

The federal and state governments have utilized a variety of policies to reduce the incidence of fatal traffic accidents. Several of these policies, such as seatbelt laws, speed limit restrictions, and insurance regulations are not limited to alcohol-impaired drivers. ${ }^{7}$ For the purposes of the present paper, however, we focus on efforts to reduce drug- and alcohol-related accidents.

Policies to reduce alcohol consumption, especially before driving, comprise one important set of efforts to reduce accident fatalities. Some US counties have declared themselves to be "dry," and generally prohibit the sale of alcohol. Despite the strong nature of these restrictions, the effectiveness of this designation in reducing alcohol-related fatalities is unclear. Brown, Jewell and Richer (1996) find that dry counties in Texas have fewer fatal motor vehicle accidents each year than wet counties, but Baughman, Conlin, Dickert-Conlin and Pepper (2001) report that these differences across counties are more likely due to countyspecific heterogeneity rather than the alcohol restrictions. Recently, Miron and Tetelbaum (2007) challenge previous beliefs that minimum legal drinking age laws had a significant impact on reducing traffic fatalities.

In addition to dry county regulations, policy makers also might use prices to reduce alcohol consumption. Several studies have found that beer taxes are associated with reductions in motor vehicle deaths. ${ }^{8}$ The apparent success of these tax policies, however, may be specious. Once state fixed effects are included in the analysis, beer taxes appear to have a negligible effect on alcohol consumption. ${ }^{9}$

\footnotetext{
${ }^{7}$ See Cohen and Einav (2003) on the effects of mandatory seat belt usage laws on traffic fatalities. Cohen and Dehejia (2004) study no-fault insurance liability laws.

${ }^{8}$ For example, see Chaloupka, Saffer and Grossman (1993), Ruhm (1995) and Cook (1991).

${ }^{9}$ See Dee (1999) and Mast, Benson and Rasmussen (1999).
} 
A second type of policy intervention is the strengthening of laws against impaired driving. Chaloupka, Saffer and Grossman (1993) compare the effectiveness of all major drunk-driving laws, and they find that punishments that include license revocation are the most successful in reducing motor vehicle deaths. By contrast, Benson, Rasmussen and Mast (1999) report that the only effective enforcement-oriented laws are those that increase the probability that a drunk driver will be pulled over by police.

In total, the empirical findings have been mixed on the effect of policy interventions on drunk driving accidents. ${ }^{10}$ One lesson to draw from these results is that there exists an inherent difficulty in inferring a causal relationship when several layers of activity separate a policy intervention from its desired outcome (e.g. a beer tax's effect on consumption, which affects whether a potential driver is impaired, which then affects safety conditional on the decision to drive). A second lesson concerns the importance of potentially unobserved local characteristics that affect drinking behavior and road safety conditions. In our analysis below, we employ a variety of empirical strategies in order to establish that the relationship between SAT and driving deaths is robust.

\section{Data}

Our data are a panel of annual county-level variables for the years 1998-2004. For a complete description of all variables and their sources, please see the data appendix. We limit our analysis to counties that have populations between 5,000 and 80,000 and are not in Metropolitan Statistical Areas (MSAs), resulting in 9,564 county-year observations. This sample covers approximately $60 \%$ of all US counties. There are two main reasons why we focus on this set of relatively small counties. First, we are focusing on situations in which both substance abuse treatment and vehicle travel are local. Data from counties in MSAs, which are characterized by frequent travel across county borders within a metropolitan area, would make it more difficult to uncover the true relationship between treatment and accidents. Second, we measure the supply of substance abuse treatment through the count of

\footnotetext{
${ }^{10}$ See Benson, Rasmussen and Mast (1999) for a discussion on how the lack of consistency in measures of deterrence across the different types of studies (microsurvey, state-level aggregates) leads to a wide range of results. The authors also provide arguments for why results of control policies are often not robust across studies.
} 
clinics. This approach to treatment supply is likely to be most informative when the number of clinics is small, as it is in non-metropolitan counties.

\subsection{Fatal Accidents}

Our data on traffic fatalities are from the Fatal Accident Reporting System (FARS), which is administered by the National Highway Traffic Safety Administration. During the years of our panel, approximately 37,000 fatal accidents occurred per year, resulting in 42,000 deaths. $^{11}$ Across the 3,140 counties in the US, this implies an average of about 12 fatal accidents per county per year. In about a third of these accidents FARS indicates that a "drinking driver" was involved. For the purposes of the analysis in this paper, we define an accident as alcohol-related if FARS indicates any type of alcohol or drug involvement. ${ }^{12}$ While the number of deaths per year increased slightly between 1998 and 2004, total alcoholrelated fatalities have declined since 2002 .

\subsection{Substance Abuse Treatment}

The primary explanatory variables of interest are measures of substance abuse treatment. These measures include the number of clinics within the county and the numbers of clinics offering outpatient and inpatient services. In 2000, approximately $15 \%$ of clinics offered both inpatient and outpatient services, and $45 \%$ of the clinics with inpatient services also offered outpatient treatment. Patients who receive outpatient treatment attend several hours of therapy per week that is scheduled around the patient's normal activities. Outpatient clinics usually offer a combination of individual and group counselling sessions. Inpatient treatment is residential, and patients who receive inpatient treatment are removed from their former surroundings. Inpatient treatment patients often travel substantial distances from their homes to the clinic.

Data on the location and characteristics of treatment facilities are from the National Survey of Substance Abuse Treatment Services (N-SSATS), an annual census of substance

\footnotetext{
${ }^{11}$ Fatal traffic accidents may involve more than one fatality (e.g., the driver and passenger).

${ }^{12}$ Alcohol and drug involvement are identified using BAC test results, drug test results, whether a driver is charged with drug or alcohol violations, or whether the police identify the driver as being impaired by alcohol or drugs.
} 
abuse treatment facilities conducted by the Substance Abuse and Mental Health Services Administration (SAMHSA). Due to temporary suspensions of the N-SSATS survey, data from 1999 and 2001 are not available.

In our sample the average number of clinics per county is 1.32 , and about $70 \%$ of counties have at least one clinic. A small number of counties have a relatively large number of clinics, so we truncate at 8 the number of clinics per county. This truncation affects only 5 of the county-year observations in our sample. ${ }^{13}$ Most (but not all) of the variation in treatment supply is cross-sectional. See Table 1 for summary statistics on SAT supply across US counties by year. The final column of Table 1 provides the percentage of counties that experience a change in the number of clinics. About $28 \%$ of counties change clinic count over the period 1998-2004.

\subsection{County Demographics and Road Safety}

There are two additional sets of explanatory variables that we employ to describe variation in traffic fatalities across counties. First, we construct a set of control variables that describe a county's demographic characteristics. We do this to capture local economic conditions and tendencies for risky behavior, which can affect driving habits, drug and alcohol consumption, and the combination of illicit substances with driving. For each year in our data we observe a county's median age, median income, the unemployment rate, percentage below the poverty line, and percentages of blacks and Hispanics. Using data from the 2000 decennial census, we also observe the fraction of divorced females and the percentages of adults who have completed high school and college.

We use a second set of control variables to describe road safety conditions. ${ }^{14}$ Due to data limitations and the level of government at which traffic laws are typically written, most of these variables are available at the state level rather than by county. We note whether a state has a primary seat belt enforcement law (i.e., drivers may be stopped for not wearing a seat belt without committing another offense), the state's level of vehicle miles traveled (VMT), traffic density, blood alcohol content (BAC) limits and maximum speed limits. The

\footnotetext{
${ }^{13}$ We also trunctate the numbers of clinics with outpatient or inpatient services (separately) at 5 .

${ }^{14}$ Our selection of road safety variables generally follows Cohen and Einav (2003) on the impact of seatbelt usage laws.
} 
maximum speed limit is 70 miles per hour in $69 \%$ of the states, and $40 \%$ of the states have a primary seat belt enforcement law. ${ }^{15}$ The maximum BAC limit is 0.08 in $63 \%$ of the states over the years 1998-2004. ${ }^{16}$ We also include the state excise tax rate on packaged beer per gallon. At the county level, we record the numbers of emergency medical personnel and hospitals to describe medical treatment quality conditional on an accident.

In Table 2 we provide summary statistics for motor vehicle fatalities and the control variables. For the county-year observations in this study, the average number of deaths per county is 6.7 and the average deaths per 10,000 residents is 3.07. The columns of Table 2 illustrate how county demographics and motor vehicle fatalities rates vary with the number of clinics in the market. The number of clinics is negatively related to both the total number of motor-vehicle fatalities and alcohol-related motor vehicle fatalities. In addition, the number of clinics appears to decrease in the percentage of residents who are black and increase with educational attainment and the median income of the county.

\subsection{Instruments}

We are concerned that unobservable local characteristics may be correlated with both the number of SAT clinics and the number of traffic fatalities. As we argued in the Introduction, SAT supply could be negatively or positively correlated with the unobservables that affect motor vehicle deaths. To address this complication, in some of the analysis below we employ instrumental variables (IV) estimators of SAT clinics' effects on motor vehicle deaths. In considering possible instruments to use within our analysis, we focus on factors which can shift the number of SAT clinics in a market without being related to local (unobservable) characteristics that affect attitudes toward drinking and road safety. We use two types of instruments below.

Our first instrument is the number of psychiatrists practicing within a county. Our logic is that SAT clinics use psychiatrists to provide services, so an increase in the number of psychiatrists reduces the cost of operating a clinic. We assume that the supply of psychiatrists

\footnotetext{
${ }^{15}$ One state changes its maximum speed limit to $70 \mathrm{mph}$ and three states change to a maximum of $75 \mathrm{mph}$ during the time period. Seven states insitute a primary seat belt enforcement law during 1998-2004.

${ }^{16}$ Thirty five of the states change their status during this time period from some other maximum to a BAC of 0.08 .
} 
is uncorrelated with the unobservable factors which may influence driving deaths. That is, psychiatrist supply is unrelated to aspects of the local culture which contribute to substance abuse, and therefore both SAT and dangerous driving. Additionally, we assume that the number of psychiatrists is exogenous to unobserved local efforts to increase road safety, such as vigorous policing of roads simultaneous with programs to encourage SAT.

In addition to psychiatrists, we employ a second set of instruments to capture the state regulatory environment regarding substance abuse treatment. In 1996, the federal government passed the Mental Health Parity Act, mandating that employers with more than 50 employees must offer coverage for mental illness equal to the lifetime and annual caps set for physical ailments. The states vary, however, in the demands made of employers and insurers. States may require that insurers provide full coverage and not merely offer it (for sale), and states may restrict the types of mental illnesses that are covered under the law and the types of firms to which regulations apply. Buchmueller, Cooper, Jacobsen and Zuvekas (2007) summarize the extent and scope of state parity legislation. ${ }^{17}$ For each state during the years 1998-2004, we utilize information on whether there is a mental health parity law that mandates benefits, and whether the mandate includes drug and alcohol abuse treatment. These indicators of the regulatory environment serve as effective instruments in that they shift the ability of SAT clinics to operate and receive payment for services. While some states introduced parity laws during our panel, unfortunately there is insufficient temporal variation to identify the effect of the laws on SAT clinics within states. We therefore use the parity regulation as an additional source of state-level cross-sectional variation in order to verify our analysis that uses other instruments or controls for heterogeneity across counties.

\section{Empirical Analysis}

The probability of an alcohol-related fatal motor vehicle accident is affected by several stages of choices. First, an agent decides whether to consume alcohol or illicit drugs. Second, the agent decides whether to operate their vehicle. Third, conditional on driving, the agent makes choices while driving (e.g. at what speed to travel), while law enforcement officials

\footnotetext{
${ }^{17}$ Information on the current status of state parity legislation can also be found from the National Conference on State Legislatures, Insure.com, and the Center for Policy Alternatives.
} 
decide how vigorously to patrol for impaired drivers. While policy interventions may occur at any of these stages, we focus primarily on the demand decisions in the first stage. We view SAT programs as a method to reduce demand for alcohol and drugs among agents whose consumption of these products may be excessive or lead to poor choices. It is also possible that while in SAT a consumer improves his ability to resist driving if he does ingest drugs or alcohol.

Our general empirical approach is to regress measures of motor vehicle deaths on measures of substance abuse treatment availability, controlling for local travel conditions and demographic characteristics. In these regressions we transform the total count of vehicle deaths into a measure of the number of deaths per 10,000 county residents. We refer to this measure of the outcome as the rate of motor vehicle deaths. ${ }^{18}$

Let Clinics $_{i t}$ represent the total number of SAT clinics in county $i$ during year $t$. Death $s_{i t}$ is the motor vehicle death rate in $i$ during $t$. The vector $D_{i t}$ contains the demographic characteristics of the county, and the vector $R_{i t}$ includes information on state- and countylevel road usage, road safety, and driving laws. The unobservable characteristics of county $i$ during $t$ are captured by the error term $\varepsilon_{i t}$. Our empirical approach is to estimate models of the form:

$$
\text { Deaths }_{i t}=f\left(\text { Clinics }_{i t} ; \theta\right)+D_{i t} \delta+R_{i t} \rho+\varepsilon_{i t} .
$$

We express the effect of Clinics $_{i t}$ on Deaths $s_{i t}$ with the function $f$ because our measures of clinics vary across empirical specifications. A related detail is that we manipulate the variable Deaths $s_{i t}$ in some specifications to include alcohol-related fatalities only or the remaining ("non-alcohol") deaths only.

Throughout the analysis below, a central concern is the nature and content of the error term $\varepsilon$. As we argued above, there are reasons to believe that $\varepsilon$ is correlated with Clinics. We take several approaches to estimating the empirical model in order to recover estimates of $\theta$ that are robust to a variety of concerns about $\varepsilon$.

\footnotetext{
${ }^{18}$ While it may be preferable to calculate the number of deaths per mile traveled, the necessary data are not available at the county level.
} 


\subsection{Correlation between clinics and motor vehicle deaths}

Our initial approach to (1) is to estimate the model with ordinary least squares (OLS) under the assumption that $\varepsilon$ is orthogonal to Clinics and the remaining explanatory variables. In addition to the demographic variables described in Section 3, we include in $D$ dummy variables for each year in the sample to capture national time trends in substance abuse treatment and road safety. We cluster standard errors by county to account for within-county correlation in $\varepsilon$ over time.

We begin by estimating the effect of Clinics on all deaths, alcohol-related deaths, and non-alcohol deaths. We report our OLS results in Table 3. With respect to all motor vehicle fatalities (Column 1), the coefficient on Clinics is negative but insignificantly different from zero. In Columns 2 and 3 we present the results for alcohol-related and non-alcohol deaths, respectively. A difference between the effect of SAT on alcohol and non-alcohol deaths is sensible if we expect the relationship between Clinics and Deaths to be driven by treatment success rather than an alternative correlation.

Our estimates of $\delta$ and $\rho$, the coefficients of the control variables, generally have the expected signs. A higher divorce rate or percentage of people living below the poverty line contributes to increased motor vehicle death rates. Mandatory seat belt law enforcement appears to reduce Deaths. We note that the formulation of the dependent variable, as a rate, implies that we interpret the population variables as measures of congestion or opportunities to travel within a county.

Despite the assumptions of the OLS models, it is likely that there is correlation between Clinics and $\varepsilon$, as we argue above. We also note that previous research on motor vehicle fatalities has illustrated the potential for unobserved market characteristics to bias the results of OLS estimates. ${ }^{19}$

\subsection{Controls for state-level unobserved characteristics}

One way to account for these unobserved characteristics is to decompose the error, $\varepsilon$, into a state-specific fixed effect and a component that varies across counties and time. That is,

\footnotetext{
${ }^{19}$ For example, see Cohen and Einav (2003); Baughman, Conlin, Dickert-Conlin and Pepper (2001); and Mast, Benson and Rasmussen (1999).
} 
we allow for $\varepsilon$ to take the form $\varepsilon_{i t}=u_{s}+e_{i t}$, where $u_{s}$ is a state-level unobservable that may be correlated with Clinics and $e_{i t}$ is a county-level error term orthogonal to substance abuse treatment. The term $u$ may reflect state-level attitudes or laws that are associated with higher amounts of addiction treatment while also affecting the incidence of impaired driving.

We re-estimate (1) with a dummy variable for each state, and we allow $e_{i t}$ to be clustered within counties over time. The results of this approach are in Table 4. The three columns of this table include the coefficient estimates for total deaths rate, alcohol-related deaths rate, and non-alcohol deaths rate with Clinics as the treatment variable of interest. Relative to the OLS results, Clinics now has a larger negative effect on total motor vehicle fatalities, and this estimate is significantly different from zero. When we separate alcohol-related deaths from non-alcohol deaths, we find that Clinics has a negative and marginally significant ( $p=$ .07 ) effect on alcohol-related deaths, but no significant impact on the remaining deaths. ${ }^{20}$ This, again, supports the interpretation that clinics have their effect on the component of death rates more closely related to their objective: to reduce alcohol and drug abuse.

We next take a finer approach to clinic activities and death rates by dividing Clinics $_{i t}$ into Outpatient ${ }_{i t}$ and Inpatient ${ }_{i t}$, which count the numbers of clinics with services of these types in county $i$ during $t$. We expect that clinics that offer outpatient treatment services would have a greater impact on local alcohol-related motor vehicle deaths than inpatient clinics, as outpatient services are consumed by local residents. Clinics that offer inpatient treatment may serve a client base with residences distant from the clinic, and therefore have limited effects on the local accident death rates. Our estimation results from this decomposition of Clinics is in Table 5. We find a negative but insignificant relationship between each type of clinic and our three measures of motor vehicle deaths. As expected, clinics providing outpatient services do not significantly reduce non-alcohol deaths, but to our surprise there is a negative and marginally significant relationship $(p=0.07)$ between inpatient clinics and non-alcohol deaths.

The results in Tables 4 and 5, which control for state-level unobserved heterogeneity,

\footnotetext{
${ }^{20}$ While the impact of Clinics on non-alcohol deaths is relatively large, this parameter is imprecisely estimated.
} 
eliminate some of the biases that were likely present in the OLS models of Table 3. Despite this improvement in the estimation approach, problematic correlation between $e_{i t}$ and Clinics $_{i t}$ may remain. If there is variation in the unobserved characteristics within a state or over time, such as within-state variation in local attitudes towards treating substance abuse, state fixed effects will not completely alleviate the endogeneity problem.

\subsection{Instrumental variables estimation}

Our final approaches to the empirical problem involve instrumental variables estimates of SAT clinics' effects on fatalities. Given that we have two sets of instruments that may be employed - psychiatrists and regulatory measures - we take an unconventional approach with these models. Rather than combining the instruments and using them all simultaneously, we use the sets of instruments separately. We do this because the state-level regulatory variables do not vary sufficiently over time to be combined with state fixed effects. While our primary results of interest use both state fixed effects and the psychiatrists instrument, we also offer estimates using the alternative instruments to verify the robustness of our results.

Results from the first stage regressions for the two sets of instruments are presented in Table 6. The number of psychiatrists is positively and significantly correlated with the number of clinics, as well as the number of clinics offering outpatient and inpatient services. The second set of instruments are the state level regulatory variables. While these regulatory measures are strongly correlated with the total number of clinics and outpatient services, they are weak with respect to the number of inpatient clinics. One striking result on Table 7 is that the presence of a law mandating benefits for mental health treatment (in general) reduces in the number of SAT clinics. We interpret the negative relationship as indicating that a mental health parity law results in non-SAT mental health services attracting resources away from substance abuse services. Parity legislation that specifically mandates drug and alcohol treatment shifts resources toward substance abuse services and is positively correlated with the number of SAT clinics.

We begin by using the total number of psychiatrists in a county as an instrument for the number of clinics. We do not yet introduce state fixed effects to the model. Because 
we are using a single instrumental variable in this analysis, we estimate separately the effects of all clinics, outpatient services, and inpatient services on various measures of traffic fatalities. Our results are presented in Table 7. The count of all SAT facilities, Clinics, has a negative and significant effect on all motor vehicle deaths $(-0.340)$ and alcohol-related deaths $(-0.210)$. The effect on non-alcohol fatalities is not significant. Clinics offering outpatient services have the same pattern of results. The coefficient estimates are negative and significant for all motor vehicle deaths and alcohol-related deaths, but not significant for nonalcohol fatalities. The impacts of additional inpatient services are smaller than outpatient effects for all three dependent variables, and follows the same pattern of significance. ${ }^{21}$

The coefficient estimates may be used to make predictions regarding the number of lives that would be saved by increasing or introducing substance abuse treatment facilities. ${ }^{22}$ We find that an additional clinic in the average county results in 0.81 fewer motor vehicle deaths per year, and 0.50 fewer alcohol-related deaths. Increasing the number of clinics that specifically offer outpatient services reduces total motor vehicle deaths by 1.44 , and alcohol-related deaths by 0.90 .

To verify our initial IV results, we repeat our analysis with the second set of instruments (state regulatory measures) and report the results in Table 8. The overall number of clinics has a significant effect on both the total motor vehicle deaths rate and the alcohol-related rate. The number of outpatient services has a marginally significant effect on the alcoholrelated death rate $(p=0.07)$. For both Clinics and outpatient services, the coefficient estimates imply reductions in alcohol-related deaths by about 0.7 per year following the addition of one clinic to a county. These estimates are comparable to those based on the results of Table 7 , which use alternative instruments. The results on inpatient clinics in Table 8 indicate no significant relationship between these services and vehicle death rates.

Finally, we utilize both state fixed effects and county-level variation in the number of

\footnotetext{
${ }^{21}$ Recall that a clinic is classified as inpatient or outpatient according to what types of services it provides, and almost half of all inpatient clinics offer both types of services. We expect inpatient facilities to have a smaller impact on local motor vehicle deaths, as the inpatient client base is less likely to be local residents.

${ }^{22}$ To calculate the reduction in deaths from increasing the number of facilities, we begin by predicting the number of motor vehicle deaths per 10,000 residents using the IV coefficient estimates. Next we increase the number of clinics in each county by one, and predict the motor vehicle deaths rate given the new number of clinics. We take the difference between the two predicted rates, multiply by the population, and then report the average as the number of lives saved.
} 
psychiatrists. We present our results from these IV models in Table 9. We find negative and significant reductions in overall motor vehicle deaths with an increase in the number of clinics, the number of clinics with outpatient services, and the number of clinics with inpatient services. The coefficients for each of the SAT measures are smaller in magnitude than the estimates from the IV model without state fixed effects (Table 7). For example, the coefficient on Clinics on all deaths is -0.218 in Table 9, about one third smaller than the comparable estimate in Table 7. The same pattern appears for alcohol-related deaths. Despite the reduced magnitudes of these coefficient estimates, the effects of additional clinics are consistently negative and significant. ${ }^{23}$ In these specifications, Clinics and the number of outpatient or inpatient services have no effect on non-alcohol deaths. The estimates from Table 9 suggest that increasing the number of clinics by one in an average county in our sample would decrease total deaths by 0.52 (8\%) and alcohol-related deaths by $0.36(14 \%)$ Specifically increasing the number of clinics offering outpatient services leads to a reduction of 0.90 total deaths (13\%) and 0.62 alcohol-related deaths (24\%). While these estimates strike us as large, it is important to note the substantial danger that habitual alcohol abusers impose on other drivers and themselves. The 2003 National Survey on Drug Use and Health reports that $0.6 \%$ of adult drivers were arrested for DUI at least once during the 12 months preceding the survey. The FARS data on auto fatalities offer an opportunity to observe a driver's number of DUI convictions during the three years before a fatal crash (not including the accident that initiated the FARS entry). About $3 \%$ of drivers in fatal crashes have prior DUI convictions, and $9.8 \%$ of all alcohol-related accidents include a drinking (or drugimpaired) driver who also has at least one prior DUI. Together, these statistics suggest that even a small number of drivers with histories of alcohol abuse can have a substantial impact on road safety.

One potential concern about our Clinics variable and (separately) the psychiatrists instrument is that these variables may be positively correlated with the quality of medical care in a market. While we already include controls for a county's numbers of hospitals and emergency medical personnel, other differences across counties may remain. If this is

\footnotetext{
${ }^{23}$ We also repeat the IV analysis including a dummy for each state-year combination. The results do not change qualitatively. We choose to use the specification with separate state and year dummies so that we are able to utilize the information on state level traffic conditions.
} 
the case, then lower death rates associated with more SAT may be due to the medical care accident victims receive, and not a reduction in impaired drivers on the road. We investigate this possibility by focusing on fatalities in which a victim is declared dead at the scene of an accident, which is the case for $57 \%$ of all accident deaths in our sample. We re-estimate the models in Table 9 for all deaths at accident scenes and report the results in Table 10. The coefficient estimates on all clinics, outpatient services, and inpatient services are each negative and significantly different from zero for alcohol-related motor vehicle fatalities at $p<0.10$, with magnitudes approximately $60 \%$ of those in Table 9 .

\section{Conclusion}

Drug and alcohol consumption leads to motor vehicle fatalities. In this paper we find that a policy of increased treatment for substance abuse problems will result in a decrease in motor vehicle related deaths. Our results imply that increasing the number of outpatient treatment facilities in the 1,918 counties in our sample reduces the number of motor vehicle deaths by 0.90 from 6.7, and the average number of alcohol-related deaths falls from 2.53 by 0.62 per year. This implies 1,726 fewer total deaths in traffic accidents per year, a $13 \%$ reduction in our sample counties. We use a variety of empirical strategies to account for unobserved characteristics that may be correlated with both treatment availability and the motor vehicle death rate. The results are robust to different techniques and we show a consistent and strong relationship between the number of treatment facilities and the motor vehicle death rate. 


\section{A Data Appendix}

1. Control Variables:

(a) Demographic data obtained from the U.S. Census and the Area Resource File.

- $\%$ Blacks - the percentage of African Americans in the county

- \% Hispanics - the percentage of people of Hispanic origin in the county

- Median Age - in years

- Median Income - in dollars (to capture current economic conditions)

- \% Poverty - percentage of people living in poverty

- Unemployment Rate - county level unemployment rate (to capture current economic conditions)

- \% College - percentage of people with college degrees in the county (2000 Decennial Census)

- \% High School - percentage of people with high school degrees in the county (2000 Decennial Census)

- \% Female Divorce - percentage of women divorced in the county (2000 Decennial Census)

- Emergency Medical Personnel

- Number of Hospitals

(b) Traffic Variables obtained from the publication "Highway Statistics" (U.S. Department of Transportation, Federal Highway Administration). All variables are at the state level.

- Traffic Density Rural - registered vehicles per unit length of rural roads in miles

- Traffic Density Urban - registered vehicles per unit length of urban roads in miles

- VMT Rural - vehicle miles traveled on rural roads

- VMT Urban - vehicle miles traveled on urban roads 
(c) Traffic/highway laws from the Insurance Institute for Highway Safety. All variables are at the state level.

- 65 m.p.h. speed limit - a dummy variable that is equal to 1 for 65 -mph top speed limit in the state

- 70 m.p.h. speed limit - a dummy variable that is equal to 1 for $70-m p h$ top speed limit in the state

- Primary Seat Belt enforcement - a dummy variable that is equal to 1 for the periods in which the state had a primary-enforcement mandatory seat belt law (police may stop and fine drivers even if the driver has not engaged in any other offense).

(d) State DUI laws from the National Conference of State Legislature.

- $\mathrm{BAC}$ of 0.08 - a dummy variable that is equal to 1 for the periods in which a state has a maximum blood alcohol content of 0.08 to qualify as DUI

(e) Crime Variables collected from the Department of Justice. ${ }^{24}$

- Violent Crimes Reported - a sum of the violent crimes per capita reported in a county (homicide, rape, robbery, aggravated assault)

- Property Crimes Reported - a sum of the property crimes per capita reported in a county (larceny, burglary, motor vehicle theft)

(f) Beer Tax Rate from the annual publication "Brewers Almanac 2007"

- State level annual excise rate on packaged beer per gallon

2. Dependent Variable: Fatalities

(a) Fatalities are obtained from the Fatalities Analysis Reporting System (FARS)

- Motor Vehicle Deaths - the number of traffic fatalities of drivers and passengers within a county during a given year.

\footnotetext{
${ }^{24}$ These crime variables control for the law enforcement status at the county level. Higher reported levels of crime may reduce the law enforcement focus on traffic violations, or it may enduce a larger police force better equipped to deal with traffic violations. We use it as a control and remain agnostic about the relationship between reported crimes and motor vehicle deaths.
} 
3. Substance Abuse Treatment

(a) County level data on SAT is obtained from the National Survey on Substance Abuse Treatment Services (N-SSATS).

- Clinics - total number of clinics operating within a county for a given year.

- Outpatient Clinics - total number of clinics that offer outpatient services within a county for a given year.

- Inpatient Clinics - total number of clinics that offer inpatient services within a county for a given year.

4. Instruments for Substance Abuse Treatment

(a) Number of Practicing Psychiatrists at the county level is obtained from the Area Resource File (ARF)

(b) State level data on regulatory environment is compiled using guidance from Buchmueller et. al. (2007), as well as from the National Conference on State Legislation, Insure.com and Center for Policy Alternatives:

- Dummy Variable for whether a state has a law mandating mental health benefits.

- Dummy variable for whether state mandate includes provision for substance abuse. 


\section{References}

[1] Baughman, Reagan, Michael Conlin, Stacy Dickert-Conlin, and John Pepper (2001). "Slippery When Wet: the Effects of Local Alcohol Access Laws on Highway Safety." Journal of Health Economics, 20: 1089-1096.

[2] Benson, Bruce L., David W. Rasmussen and Brent D. Mast (1999). "Deterring Drunk Driving Fatalities: An Economics of Crime Perspective." International Review of Law and Economics, 19: 205-225.

[3] Brown, Robert W., R. Todd Jewell and Jerrell Richer (1996). "Endogenous Alcohol Prohibition and Drunk Driving." Southern Economic Journal, 62(4): 1043-1053.

[4] Buchmueller, Thomas C., Philip F. Cooper, Mireille Jacobson and Samuel H. Zuvekas (2007). "Parity for Whom? Exemptions and the Extent of State Mental Health Parity Legislation." Health Affairs, 26(4): 483-487.

[5] Cartwright, William (2000). "Cost-Benefit Analysis of Drug Treatment Services: Review of the Literature." The Journal of Mental Health Policy and Economics, 3(1): 11-26.

[6] Chaloupka, Frank J., Henry Saffer and Michael Grossman (1993). "Alcohol-Control Policies and Motor-Vehicle Fatalities." The Journal of Legal Studies, 22(1): 161-186.

[7] Cohen, Alma and Rajeev Dehejia (2004). "The Effect of Automobile Insurance and Accident Liability Laws on Traffic Fatalities." Journal of Law and Economics, 47: 357393.

[8] Cohen, Alma and Liran Einav (2003). "The Effects of Mandatory Seat Belt Laws on Driving Behavior and Traffic Fatalities." The Review of Economics and Statistics, 85(4): 828-843.

[9] Cook, Philip J. (1981). "The Effect of Liquor Taxes on Drinking, Cirrhosis and Auto Accidents." In Alcohol and Public Policy: Beyond the Shadow of Prohibition, edited by Mark H. Moore and Daniel R. Gerstein. Washington DC: National Academy Press, $255-285$. 
[10] Dee, Thomas S. (1999). "State Alcohol Policies, Teen Drinking and Traffic Fatalities." Journal of Public Economics, 72: 289-315.

[11] Hingson, RW, RC Zakocs, T Heeren, MR Winter D Rosenbloom and W DeJong (2005). "Effects on alcohol related fatal crashes of a community based initiative to increase substance abuse treatment and reduce alcohol availability." Injury Prevention, 11: 8490

[12] Levitt, Steven and Jack Porter (2001). "How Dangerous Are Drinking Drivers?" Journal of Political Economy 109(6): 1198-1237.

[13] Lu, Misgshan and Thomas McGuire (2002). "The Productivity of Outpatient Treatment for Substance Abuse." The Journal of Human Resources, 37(2): 309-335.

[14] Mast, Brent D., Bruce L. Benson and David W. Rasmussen (1999). "Beer Taxation and Alcohol-Related Traffic Fatalities." Southern Economic Journal, 66(2): 214-249.

[15] Miron, Jeffrey A., and Elina Tetelbaum (2007). "Does the Minimum Legal Drinking Age Save Lives?" NBER Working Paper No. 13257.

[16] Prengergast, Michael L., Deborah Podus, Eunice Chang, and Darren Urada (2002). "The Effectiveness of Drug Abuse Treatment: A Meta-Analysis of Comparison Group Studies." Drug and Alcohol Dependence, 67(1): 53-72.

[17] Ruhm, Christopher J. (1996). "Alcohol Policies and Highway Vehicle Fatalities." Journal of Health Economics, 15: 435-445.

[18] Rydell, C. Peter and Susan S. Everingham (1994). "Controlling Cocaine: Supply Versus Demand Programs". RAND Report.

[19] Saffer, Henry (1997). "Alcohol Advertising and Motor Vehicle Fatalities." The Review of Economics and Statistics, 79(3): 431-442.

[20] Saffer, Henry, Frank Chaloupka, and Dhaval Dave (2001). "State drug control spending and illicit drug participation." Contemporary Economic Policy, 19(2): 150-161. 
[21] U.S. Dept. of Health and Human Services, Substance Abuse and Mental Health Services Administration. (2004). Results from the 2003 National Survey on Drug Use and Health: National Findings (Office of Applied Studies, NSDUH Series H-25, DHHS Publication No. SMA 07-3964).

[22] U.S. Dept. of Health and Human Services, Substance Abuse and Mental Health Services Administration. (2007). Results from the 2006 National Survey on Drug Use and Health: National Findings (Office of Applied Studies, NSDUH Series H-32, DHHS Publication No. SMA 07-4293). 
Table 1:

Number of clinics by year

\begin{tabular}{ccccc}
\hline \hline YEAR & $\begin{array}{c}\text { Average Number of } \\
\text { Clinics in County }\end{array}$ & $\begin{array}{c}\text { \% Counties with } \\
\text { Clinic Presence }\end{array}$ & $\begin{array}{c}\text { \% Counties with } \\
\text { Outpatient Presence }\end{array}$ & $\begin{array}{c}\text { \% Counties with } \\
\text { Change in Clinic Count }\end{array}$ \\
\hline 1998 & 1.316 & 65.38 & 62.41 & - \\
2000 & 1.337 & 70.28 & 69.13 & 41.87 \\
2002 & 1.340 & 70.51 & 68.90 & 27.91 \\
2003 & 1.327 & 69.69 & 68.17 & 22.04 \\
2004 & 1.302 & 69.20 & 67.68 & 19.73 \\
& & & & \\
Average & 1.324 & 69.01 & 67.26 & 27.91 \\
\hline \hline
\end{tabular}

Table 2:

Summary statistics on motor vehicle fatalities, SAT supply, and other control variables

\begin{tabular}{lcccc}
\hline \hline & All Counties & Zero Clinics & One Clinic & Two + Clinics \\
\hline Motor Vehicle Fatalities per 10,000 & 3.0762 & 3.5098 & 3.0735 & 2.6573 \\
Alcohol-Related Motor Vehicle & 0.9754 & 1.1039 & 0.9882 & 0.8355 \\
Fatalities per 10,000 & 23,941 & 15,079 & 21,266 & 35,690 \\
\hline Population & 9.24 & 11.34 & 10.15 & 6.145 \\
\% Black & 5.72 & 6.873 & 4.509 & 6.003 \\
\% Hispanic & 37.96 & 38.49 & 38.17 & 37.21 \\
Median Age & 75.22 & 73.09 & 74.84 & 77.76 \\
\% HS Grad & 13.98 & 12.50 & 13.47 & 16.01 \\
\% College grad & 9.683 & 8.977 & 9.624 & 10.44 \\
\% Females Divorced & 14.93 & 15.59 & 15.02 & 14.17 \\
\% Poverty & 33,383 & 32,123 & 33,207 & 34,814 \\
Median Income & 5.766 & 5.610 & 5.840 & 5.832 \\
\% Unemployment & 0.418 & 0.483 & 0.379 & 0.399 \\
VMT Urban / 100,000 & 0.299 & 0.341 & 0.287 & 0.271 \\
VMT Rural & 539.60 & 276.60 & 433.81 & 919.17 \\
Property Crimes Reported & 59.502 & 34.813 & 54.413 & 89.479 \\
Violent Crimes Reported & 262.30 & 250.82 & 268.21 & 266.57 \\
Traffic Density (Urban) & 64.562 & 57.309 & 65.409 & 70.632 \\
Traffic Density (Rural) & 0.6363 & 0.6535 & 0.6251 & 0.6325 \\
BAC of 0.08 & 0.3971 & 0.4470 & 0.3718 & 0.3780 \\
Standard Seat Belt Enforcement & 69.326 & 82.085 & 64.904 & 62.069 \\
Speed Limit 70mph & 30.622 & 17.915 & 35.096 & 37.767 \\
Speed Limit 65mph & 9565 & 2964 & 3556 & 3045 \\
$N$ & & & & \\
\hline \hline
\end{tabular}


Table 3

The estimated effect of SAT on traffic fatalities using ordinary least squares

\begin{tabular}{|c|c|c|c|c|c|c|}
\hline Dependent Variable: & All deaths & t-stat & $\begin{array}{c}\text { Alcohol } \\
\text { deaths }\end{array}$ & t-stat & $\begin{array}{c}\text { Non- } \\
\text { alcohol } \\
\text { deaths }\end{array}$ & t-stat \\
\hline Number of Clinics & -0.027 & -1.22 & -0.018 & -1.54 & -0.009 & -0.54 \\
\hline Population & -0.544 & -7.33 & -0.211 & -5.61 & -0.333 & -5.86 \\
\hline Population-Squared & 5.793 & 6.39 & 2.289 & 5.06 & 3.504 & 5.05 \\
\hline$\%$ Black & 1.049 & 2.86 & -0.229 & -1.32 & 1.279 & 4.81 \\
\hline \% Hispanic & 0.998 & 1.78 & -0.165 & -0.65 & 1.162 & 2.63 \\
\hline Median Age & -0.004 & -0.30 & 0.011 & 1.70 & -0.015 & -1.38 \\
\hline$\%$ Poverty & 0.039 & 1.94 & 0.052 & 4.36 & -0.014 & -1.04 \\
\hline Median Income & 0.064 & 0.56 & 0.138 & 2.18 & -0.074 & -0.92 \\
\hline \% Unemployment & -0.037 & -1.96 & -0.010 & -0.99 & -0.027 & -1.86 \\
\hline \% HS Grad & 0.003 & 0.39 & 0.004 & 0.92 & -0.001 & -0.14 \\
\hline \% College grad & -0.033 & -3.54 & -0.004 & -0.80 & -0.029 & -4.19 \\
\hline \% Females Divorced & 0.083 & 3.97 & 0.045 & 4.72 & 0.037 & 2.27 \\
\hline VMT Urban & 0.615 & 2.57 & 0.450 & 3.88 & 0.165 & 0.98 \\
\hline VMT Rural & -1.162 & -2.58 & -0.749 & -3.40 & -0.413 & -1.25 \\
\hline Property Crimes Reported & -0.318 & -4.60 & -0.181 & -5.05 & -0.138 & -2.68 \\
\hline Violent Crimes Reported & 1.543 & 3.42 & 1.358 & 5.48 & 0.185 & 0.60 \\
\hline Traffic Density (Urban) & -0.301 & -4.31 & 0.069 & 1.70 & -0.371 & -7.58 \\
\hline Traffic Density (Rural) & -0.157 & -1.34 & -0.054 & -0.99 & -0.103 & -1.30 \\
\hline BAC of 0.08 & -0.008 & -0.11 & -0.059 & -1.57 & 0.051 & 0.96 \\
\hline Standard Seat Belt Enforcement & -0.304 & -4.59 & -0.216 & -6.45 & -0.088 & -1.79 \\
\hline Speed Limit 70mph & -0.119 & -0.29 & -0.062 & -0.34 & -0.057 & -0.19 \\
\hline Speed Limit 65mph & -0.770 & -1.95 & -0.337 & -1.90 & -0.433 & -1.53 \\
\hline Emergency Personnel & -0.006 & -0.39 & -0.012 & -1.58 & 0.006 & 0.60 \\
\hline Hospitals & -0.070 & -1.41 & -0.025 & -0.99 & -0.044 & -1.19 \\
\hline Beer Tax Rate & -0.149 & -0.77 & -0.164 & -1.70 & 0.015 & 0.11 \\
\hline Constant & 4.247 & 3.36 & -0.549 & -0.85 & 4.796 & 5.16 \\
\hline Number of Observations & \multicolumn{2}{|c|}{9564} & \multicolumn{2}{|c|}{9564} & \multicolumn{2}{|c|}{9564} \\
\hline $\mathrm{R}^{2}$ & \multicolumn{2}{|c|}{0.1294} & \multicolumn{2}{|c|}{0.0809} & \multicolumn{2}{|c|}{0.1082} \\
\hline
\end{tabular}

Note: A dummy variable for each year is also included but not reported. Standard errors are clustered by county. Coefficient estimates are in bold if they are significantly different from zero with $p<.05$. 
Table 4

The estimated effect of SAT on traffic fatalities with state fixed effects

\begin{tabular}{|c|c|c|c|c|c|c|}
\hline Dependent Variable: & All deaths & t-stat & $\begin{array}{c}\text { Alcohol } \\
\text { deaths }\end{array}$ & t-stat & $\begin{array}{c}\text { Non- } \\
\text { alcohol } \\
\text { deaths }\end{array}$ & t-stat \\
\hline Number of Clinics & -0.045 & -2.00 & -0.021 & -1.81 & -0.024 & -1.45 \\
\hline Population & -0.536 & -7.23 & -0.190 & -5.03 & -0.346 & -6.29 \\
\hline Population-Squared & 5.971 & 6.77 & 2.024 & 4.60 & 3.947 & 5.96 \\
\hline \% Black & 1.190 & 3.00 & 0.051 & 0.27 & 1.139 & 3.99 \\
\hline \% Hispanic & -0.985 & -1.74 & -0.836 & -3.03 & -0.149 & -0.36 \\
\hline Median Age & 0.002 & 0.17 & 0.006 & 0.83 & -0.004 & -0.40 \\
\hline \% Poverty & 0.021 & 0.98 & 0.044 & 3.44 & -0.023 & -1.79 \\
\hline Median Income & 0.088 & 0.72 & 0.162 & 2.33 & -0.075 & -0.91 \\
\hline \% Unemployment & -0.036 & -1.71 & -0.006 & -0.60 & -0.030 & -1.78 \\
\hline \% HS Grad & -0.018 & -1.71 & -0.007 & -1.37 & -0.011 & -1.53 \\
\hline \% College grad & -0.030 & -3.05 & -0.006 & -1.26 & -0.024 & -3.34 \\
\hline \% Females Divorced & 0.052 & 2.24 & 0.026 & 2.07 & 0.027 & 1.62 \\
\hline VMT Urban & 0.740 & 0.87 & 0.407 & 0.67 & 0.333 & 0.46 \\
\hline VMT Rural & -0.797 & -0.68 & -0.481 & -0.69 & -0.316 & -0.33 \\
\hline Property Crimes Reported & -0.254 & -3.31 & -0.144 & -3.83 & -0.110 & -1.99 \\
\hline Violent Crimes Reported & 0.675 & 1.22 & 0.903 & 3.34 & -0.228 & -0.56 \\
\hline Traffic Density (Urban) & 0.244 & 1.69 & 0.092 & 1.06 & 0.152 & 1.42 \\
\hline Traffic Density (Rural) & -0.108 & -0.47 & -0.045 & -0.29 & -0.063 & -0.35 \\
\hline BAC of 0.08 & -0.137 & -1.91 & -0.093 & -2.10 & -0.044 & -0.79 \\
\hline Standard Seat Belt Enforcement & 0.037 & 0.41 & -0.024 & -0.38 & 0.061 & 0.84 \\
\hline Speed Limit 65mph & -0.118 & -0.53 & -0.289 & -1.41 & 0.171 & 0.77 \\
\hline Speed Limit 70mph & \multicolumn{2}{|c|}{ (dropped) } & \multicolumn{2}{|c|}{ (dropped) } & \multicolumn{2}{|c|}{ (dropped) } \\
\hline Emergency Personnel & -0.031 & -2.02 & -0.012 & -1.53 & -0.019 & -1.67 \\
\hline Hospitals & -0.067 & -1.50 & -0.033 & -1.41 & -0.035 & -1.04 \\
\hline Beer Tax Rate & 0.271 & 0.46 & 0.069 & 0.21 & 0.202 & 0.42 \\
\hline Constant & 4.247 & 3.03 & 0.302 & 0.41 & 3.945 & 3.81 \\
\hline Number of Observations & \multicolumn{2}{|c|}{9564} & \multicolumn{2}{|c|}{9564} & \multicolumn{2}{|c|}{9564} \\
\hline $\mathrm{R}^{2}$ (Overall) & \multicolumn{2}{|c|}{0.1797} & \multicolumn{2}{|c|}{0.1256} & \multicolumn{2}{|c|}{0.1668} \\
\hline
\end{tabular}

Note: A dummy variable for each year is also included but not reported. Standard errors are clustered by county. Coefficient estimates are in bold if they are significantly different from zero with $p<.05$. 
Table 5

The estimated effect of SAT on traffic fatalities with state fixed effects.

SAT services separated by outpatient and inpatient.

\begin{tabular}{lcccccc}
\hline \hline Dependent Variable: & All deaths & t-stat & $\begin{array}{c}\text { Alcohol } \\
\text { deaths }\end{array}$ & t-stat & $\begin{array}{c}\text { Non- } \\
\text { alcohol } \\
\text { deaths }\end{array}$ & t-stat \\
\hline & & & & & & -0.86 \\
Outpatient services present & -0.039 & -1.34 & -0.021 & -1.39 & -0.018 & -1.82 \\
Inpatient services present & -0.047 & -1.21 & -0.004 & -0.19 & -0.051 & \\
\hline \hline
\end{tabular}

Note: Standard errors are clustered by county. Coefficient estimates are in bold if they are significantly different from zero with $p<.05$. The models also include the control variables listed in Tables 3 and 4 , plus a set of year dummy variables. The full results are available upon request.

Table 6

First-stage models to predict SAT services

\begin{tabular}{|c|c|c|c|c|c|c|}
\hline Dependent Variable: & Clinics & t-stat & $\begin{array}{l}\text { Outpatient } \\
\text { clinics } \\
\end{array}$ & t-stat & $\begin{array}{l}\text { Inpatient } \\
\text { clinics }\end{array}$ & t-stat \\
\hline \multicolumn{7}{|c|}{ Model 1: Effect of psychiatrists on SAT measures } \\
\hline Number of Psychiatrists & 0.112 & 5.26 & 0.063 & 4.63 & 0.081 & 5.73 \\
\hline \multicolumn{7}{|c|}{ Model 2:Effect of State Mandates on SAT measures } \\
\hline Mandated Benefits State Law & -0.230 & -3.91 & -0.241 & -5.47 & -0.004 & -0.11 \\
\hline $\begin{array}{l}\text { Mandated Drug and Alcohol } \\
\text { Benefits State Law }\end{array}$ & 0.235 & 4.91 & 0.186 & 4.79 & 0.036 & 1.24 \\
\hline
\end{tabular}

Notes: Results reported are limited to the variables that are used as instruments in the following IV estimation (psychiatrists and state regulations). Standard errors are clustered by county. Coefficient estimates are in bold if they are significantly different from with $p<.05$. The models also include the control variables listed in Tables 3 and 4 , plus a set of year dummy variables. The full results are available upon request. 
Table 7

The estimated effect of SAT on traffic fatalities using instrumental variables, with psychiatrists as the instrument

\begin{tabular}{|c|c|c|c|c|c|c|}
\hline Dependent Variable: & All deaths & t-stat & $\begin{array}{c}\text { Alcohol } \\
\text { deaths }\end{array}$ & t-stat & $\begin{array}{c}\text { Non- } \\
\text { alcohol } \\
\text { deaths }\end{array}$ & t-stat \\
\hline \multicolumn{7}{|c|}{ Model 1: Effect of total SAT on deaths } \\
\hline Number of clinics & -0.340 & -2.66 & -0.210 & -2.98 & -0.130 & -1.51 \\
\hline \multicolumn{7}{|c|}{ Model 2: Effect of outpatient SAT on deaths } \\
\hline Number of outpatient clinics & -0.605 & -2.50 & -0.374 & -2.72 & -0.231 & -1.49 \\
\hline \multicolumn{7}{|c|}{ Model 3: Effect of inpatient SAT on deaths } \\
\hline Number of inpatient clinics & -0.466 & -2.86 & -0.288 & -3.19 & -0.178 & -1.55 \\
\hline
\end{tabular}

Notes: Coefficient estimates are in bold if they are significantly different from with $p<.05$. Standard errors are clustered by county. We report here the SAT clinic variables only. The models also include the control variables listed in Tables 3 and 4, plus a set of year dummy variables. The full results are available upon request.

Table 8

The estimated effect of SAT on traffic fatalities using instrumental variables, with mandate laws as the instruments

\begin{tabular}{|c|c|c|c|c|c|c|}
\hline Dependent Variable: & All deaths & t-stat & $\begin{array}{c}\text { Alcohol } \\
\text { deaths }\end{array}$ & t-stat & $\begin{array}{c}\text { Non- } \\
\text { alcohol } \\
\text { MVD }\end{array}$ & t-stat \\
\hline \multicolumn{7}{|c|}{ Model 1: Effect of total SAT on deaths } \\
\hline Number of clinics & -0.547 & -2.03 & -0.296 & -2.18 & -0.251 & -1.27 \\
\hline \multicolumn{7}{|c|}{ Model 2: Effect of outpatient SAT on deaths } \\
\hline Number of outpatient clinics & -0.395 & -1.41 & -0.271 & -1.85 & -0.124 & -0.60 \\
\hline \multicolumn{7}{|c|}{ Model 3: Effect of inpatient SAT on deaths } \\
\hline Number of inpatient clinics & -7.310 & -1.23 & -2.494 & -1.15 & -4.816 & -1.21 \\
\hline
\end{tabular}

Notes: Coefficient estimates are in bold if they are significantly different from with $p<.05$. Standard errors are clustered by county. We report here the SAT clinic variables only. The models also include the control variables listed in Tables 3 and 4, plus a set of year dummy variables. The full results are available upon request. 
Table 9

The estimated effect of SAT on traffic fatalities with state fixed effects and psychiatrists as an instrument

\begin{tabular}{|c|c|c|c|c|c|c|}
\hline Dependent Variable: & All deaths & t-stat & $\begin{array}{c}\text { Alcohol } \\
\text { deaths }\end{array}$ & t-stat & $\begin{array}{c}\text { Non- } \\
\text { alcohol } \\
\text { deaths }\end{array}$ & t-stat \\
\hline \multicolumn{7}{|c|}{ Model 1: Effect of total SAT on deaths } \\
\hline Number of clinics & -0.218 & -2.00 & -0.149 & -2.43 & -0.070 & -0.91 \\
\hline \multicolumn{7}{|c|}{ Model 2: Effect of outpatient SAT on deaths } \\
\hline Number of outpatient clinics & -0.377 & -1.94 & -0.257 & -2.30 & -0.120 & -0.91 \\
\hline \multicolumn{7}{|c|}{ Model 3: Effect of inpatient SAT on deaths } \\
\hline Number of inpatient clinics & -0.300 & -2.07 & -0.204 & -2.50 & -0.095 & -0.92 \\
\hline
\end{tabular}

Notes: Coefficient estimates are in bold if they are significantly different from with $p<.05$. Standard errors are clustered by county. We report here the SAT clinic variables only. The models also include the control variables listed in Tables 3 and 4, plus a set of year dummy variables. The full results are available upon request.

Table 10

The estimated effect of SAT on deaths at the scene of accidents with state fixed effects and psychiatrists as an instrument

\begin{tabular}{|c|c|c|c|c|c|c|}
\hline Dependent Variable: & All deaths & t-stat & $\begin{array}{c}\text { Alcohol } \\
\text { deaths }\end{array}$ & t-stat & $\begin{array}{c}\text { Non- } \\
\text { alcohol } \\
\text { deaths }\end{array}$ & t-stat \\
\hline \multicolumn{7}{|c|}{ Model 1: Effect of total SAT on deaths } \\
\hline Number of clinics & -0.130 & -1.56 & -0.084 & -1.88 & -0.046 & -0.78 \\
\hline \multicolumn{7}{|c|}{ Model 2: Effect of outpatient SAT on deaths } \\
\hline Number of outpatient clinics & -0.224 & -1.52 & -0.145 & -1.81 & -0.079 & -0.78 \\
\hline \multicolumn{7}{|c|}{ Model 3: Effect of inpatient SAT on deaths } \\
\hline Number of inpatient clinics & -0.178 & -1.60 & -0.115 & -1.89 & -0.063 & -0.79 \\
\hline
\end{tabular}

Notes: Coefficient estimates are in bold if they are significantly different from with $p<.05$. Standard errors are clustered by county. We report here the SAT clinic variables only. The models also include the control variables listed in Tables 3 and 4, plus a set of year dummy variables. The full results are available upon request. 